\title{
Surface Crystallization in Mg-Based Bulk Metallic Glass during Copper Mold Casting
}

\author{
Xin Wang \\ School of Material Science and Engineering, Hebei University of Technology, Dingzigu Road, Hongqiao District, \\ Tianjin 300130, China
}

Correspondence should be addressed to Xin Wang; ahaxin@126.com

Received 21 March 2014; Accepted 18 April 2014; Published 6 May 2014

Academic Editor: Yang Shao

Copyright (C) 2014 Xin Wang. This is an open access article distributed under the Creative Commons Attribution License, which permits unrestricted use, distribution, and reproduction in any medium, provided the original work is properly cited.

The localized crystallization of $\mathrm{Mg}_{54} \mathrm{Cu}_{28} \mathrm{Ag}_{7} \mathrm{Y}_{11}$ bulk metallic glass (BMG) in the injection casting process using a copper mold was investigated. It has been found that several crystalline phases were formed close to the as-cast surface but did not exist in the internal part of the BMG plate. It is abnormal that the as-cast surface is partially crystallized with higher cooling rate than that of inside. Overheating of the melt and nucleation induced by the surface of copper mold play key roles in the abnormal crystallization. It is suggested that the function of copper mold to trigger heterogeneous nucleation cannot be totally ignored, although it provides the high cooling rate for the glass formation during casting.

\section{Introduction}

Bulk metallic glass (BMG) has attracted much attention since the rapid cooling solidification technology was developed which mainly includes melt quenching, fluxing, and copper mold casting [1-4]. The unique structure of metallic glass (MG) formed by rapid cooling solidification endows this new comer of metal materials many special properties such as good compression ductility, high corrosion resistance, good wear resistance, and special functional properties [5-14]. In general, BMG is fabricated by quenching the melt without incurring crystallization. Therefore, the forming of MG is determined by the inherent glass forming ability (GFA) of the alloy itself and the preparation conditions. Meanwhile, the GFA of one alloy is the major factor to control the thermal stability of the glass forming liquid. The other factor, which is related to the preparation technologies, also plays an important role to obtain full amorphous structure frozen from the melt.

Mg-based BMG is one-kind lightweight amorphous alloy, few in amount, which possesses both good GFA and low density. Inoue et al. [15] firstly discovered the $\mathrm{Mg}_{65} \mathrm{Cu}_{25} \mathrm{Y}_{10} \mathrm{BMG}$ in 1991. Next, Park et al. [16] investigated the effect of Ag substitution for $\mathrm{Cu}$ and improved the critical diameter $\left(D_{c}\right)$ for amorphous phase formation from $4 \mathrm{~mm}$ to $6 \mathrm{~mm}$. Ma et al.
$[17,18]$ optimized the composition of $\mathrm{Mg}-\mathrm{Cu}-\mathrm{Y}$ ternary alloy and $\mathrm{Mg}-\mathrm{Cu}-\mathrm{Ag}-\mathrm{Y}$ quaternary alloy, improving the $D_{c}$ values to $9 \mathrm{~mm}$ and $16 \mathrm{~mm}$, respectively. Up to date, this class of BMG can be made into $27 \mathrm{~mm}$ [19] and can be significantly toughened by ex situ addition of some second phases [20, 21]. Therefore, Mg-based BMG and composites have been regarded as promising materials for engineering application. It is necessary to investigate the processing properties of this BMG alloy system.

In the present work, $\mathrm{Mg}_{54} \mathrm{Cu}_{28} \mathrm{Ag}_{7} \mathrm{Y}_{11}$ alloy [18] was selected as the experimental material to investigate the casting formability of typical Mg-based BMG. The crystallization related to the cast technology aspect will be discussed.

\section{Experimental}

The raw materials with purity better than $99.9 \%$ were used to fabricate the BMG alloy. An intermediate alloy with the nominal composition $\mathrm{Cu}_{28} \mathrm{Ag}_{7} \mathrm{Y}_{11}$ was firstly prepared by arc melting method under a Ti-gettered argon atmosphere. This intermediate alloy was then melted with $\mathrm{Mg}$ pieces by induction melting under inert atmosphere to obtain a master alloy with the nominal composition $\mathrm{Mg}_{54} \mathrm{Cu}_{28} \mathrm{Ag}_{7} \mathrm{Y}_{11}$. Subsequently, the master alloy was then remelted in the quartz 


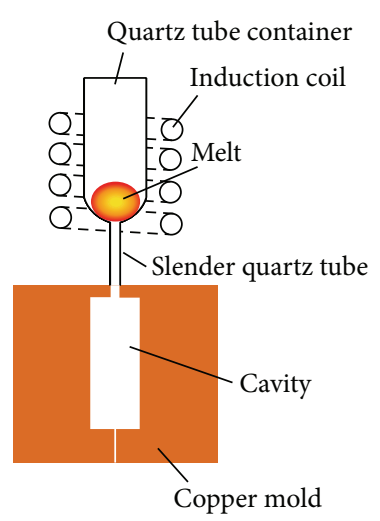

(a)

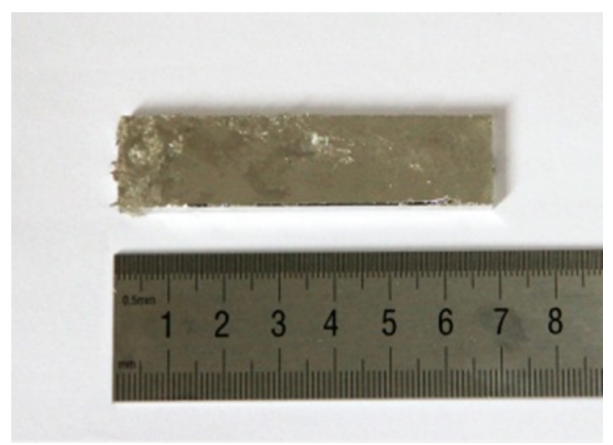

(b)

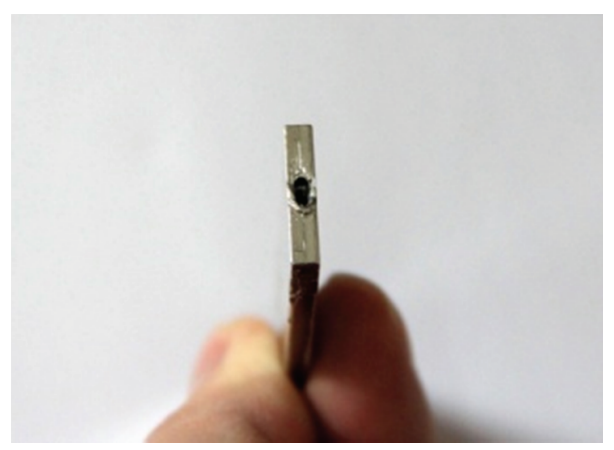

(c)

FIGURE 1: (a) Schematic diagram of the applied injection casting, (b) image of the BMG plate, and (c) top view of the plate.

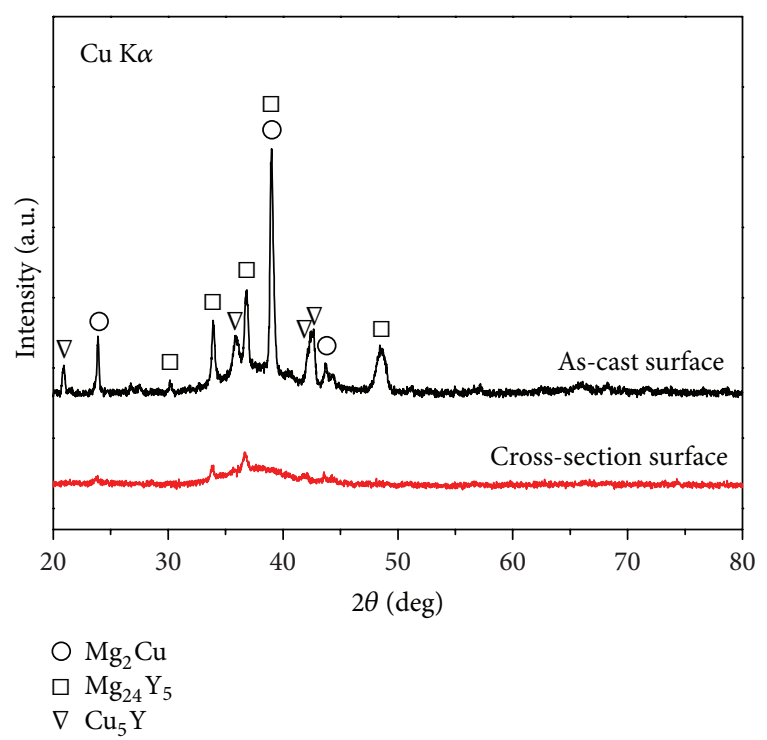

FIGURE 2: XRD spectra of the $\mathrm{Mg}_{54} \mathrm{Cu}_{28} \mathrm{Ag}_{7} \mathrm{Y}_{11}$ plate for different parts.

tubes using induction melting and injected into the copper mold which had an internal plate-shaped cavity of about 3 $\times 14 \times 70 \mathrm{~mm}$ in size. The applied injection casting method was optimized by Xie et al. [22] as shown in Figure 1(a). A slender quartz tube was placed between the quartz tube (melt container) and the mold to keep gas impermeability for improving the mold-filling capacity.

The as-cast BMG sample was examined by X-ray diffraction (XRD) analysis using Rigaku D/max-RB XRD spectrometry with $\mathrm{Cu} \mathrm{K} \alpha$ radiation. The thermal stability of the as-cast BMG sample was measured by differential scanning calorimeter (DSC, TA Instruments) at a constant heating rate of $20 \mathrm{~K} / \mathrm{min}$. The surface morphology was investigated by a LEO1530 scanning electron microscope (SEM) with a field emission gun. The composition of the BMG samples was examined by energy dispersive X-ray spectroscopy (EDS).

\section{Results and Discussion}

Figure 1 shows the pictures of one cast plate together with the schematic diagram of the applied injection casting. The as-cast plate has a perfect shape which completely matches the cavity size of the copper mold as shown in Figures 1 (b) and 1(c). The good mold-filling capacity is attributed to the following two aspects: the good gas impermeability and a higher cast temperature of the melt. The good gas impermeability is favorable for improving the pressure of the melt during filling in the mold. Overheating is beneficial for improving the fluidity of the melt. These two aspects collaboratively work, resulting in significant improvement of mold-filling capacity.

Figure 2 shows the XRD spectra of the as-cast surface and the cross-section surface of the $\mathrm{Mg}_{54} \mathrm{Cu}_{28} \mathrm{Ag}_{7} \mathrm{Y}_{11}$ alloy plate. 
It was found that the spectrum of the as-cast surface has many sharp peaks corresponding to the crystalline phases such as $\mathrm{Mg}_{2} \mathrm{Cu}, \mathrm{Mg}_{24} \mathrm{Y}_{5}$ and $\mathrm{Cu}_{5} \mathrm{Y}$. However, for the cross-section, the intensities of the crystalline phase peaks are much lower than that of the as-cast surface. It was demonstrated that the amount of crystalline phase in the cross-section surface is smaller than that of the as-cast surface. Moreover, one typical amorphous structure feature, the hump-like diffuse scattering peak, can be identified as existing on the spectrum of the cross-section surface. It is then suggested that the plate contains certain amount of amorphous phase. As we speculated, the crystalline phases might be precipitated in the as-cast surface in contact with the copper mold.

The as-cast sample, which has been examined by XRD in Figure 2, was grinded using sandpaper and hereafter reexamined to confirm whether the crystallization partially occurs on the surface. After wearing off $\sim 0.1 \mathrm{~mm}$ and $\sim 0.2 \mathrm{~mm}$ from the as-cast surface, the sample was rescanned by XRD, respectively. Figure 3 displays the XRD spectra of the sample with different wear depths. It shows that the intensities of the crystalline phase peaks are decreased with the increased wear depth. Moreover, the sample is found to be composed of full amorphous structure after wearing off $\sim 0.2 \mathrm{~mm}$. The inset of Figure 3 shows the DSC curve of the sample after wearing. It possesses a typical glass transition followed by an obvious crystallization process which is consistent with the result in the earlier work [18]. It is demonstrated again that the centre part of the as-cast plate possesses a full amorphous structure.

Figure 4 shows a typical backscattered electron image of the sample after wearing off $\sim 0.1 \mathrm{~mm}$ in depth. It is clearly observed that some phases, with simple geometric shapes such as triangle, quadrilateral, and hexagon, are existing on the worn surface which is near the as-cast surface. A further examination on these polygon phases by EDX proved that they are all $\mathrm{Cu}$-rich and Y-rich. The ratio of $\mathrm{Cu}$ and $\mathrm{Y}$ in atom is less than $6: 1$. It is considered that, by combining this result with the XRD spectra shown in Figure 2, this phase may be $\mathrm{Cu}_{5} \mathrm{Y}$, a common compound in ternary $\mathrm{Mg}-\mathrm{Cu}-\mathrm{Y}$ alloys. The investigation result shown in Figure 4 agrees well with the discovery in a very recent work by Mezbahul-Islam and Medraj [23]. They reported on the phase formation in the ternary $\mathrm{Mg}-\mathrm{Cu}-\mathrm{Y}$ system, revealing that the metallographic shapes of the phases with $\mathrm{Cu}$-rich and Y-rich have small plane features as well as simple geometric shapes.

For copper mold casting, it has been reported that the cooling rate is decreased with the increased diameter size. In other words, the center of a rod or plate should have relatively lower cooling rates which negatively affect the glass forming. Therefore, the crystallization is mostly identified in the center region $[24,25]$. However, the crystallization in the present work is quite different: the major crystalline phases are all segregation on the as-cast surface where the cooling rate is relatively higher. It is thus suggested that the copper mold does not completely play a single role to supply the high cooling rate for glass formation.

The possible reason of the abnormal crystallization may be attributed to the two following aspects. The first one is that the GFA of the $\mathrm{Mg}_{54} \mathrm{Cu}_{28} \mathrm{Ag}_{7} \mathrm{Y}_{11}$ alloy is decreased by some preparation technologies such as the cast temperature

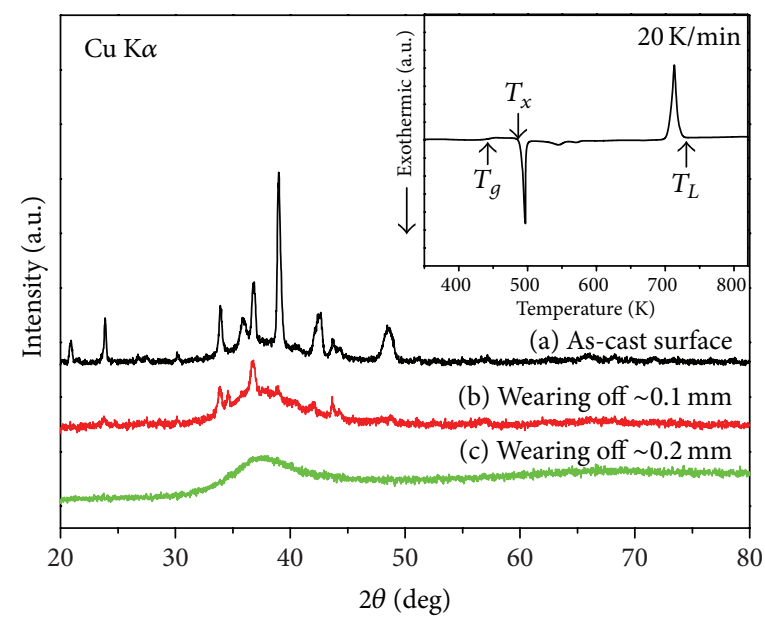

FIGURE 3: XRD spectra of the $\mathrm{Mg}_{54} \mathrm{Cu}_{28} \mathrm{Ag}_{7} \mathrm{Y}_{11}$ plate with different surface treatments. The inset is the DSC curve of the sample after wearing off the crystalline surface.

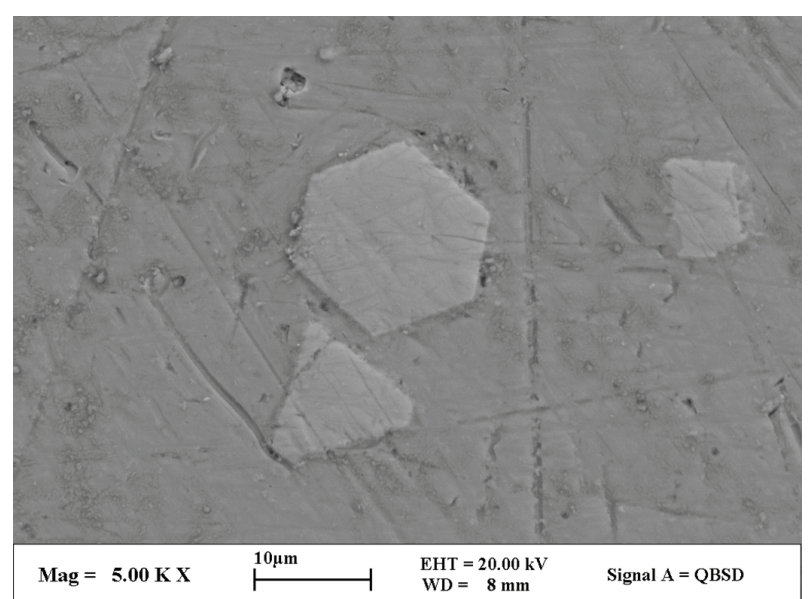

FIGURE 4: Typical BSE image of some crystalline phases near the ascast surface.

and the use of quartz tube. It is known that overheating of the melt significantly affects the GFA of BMG [26]. In this work, a higher cast temperature together with a high Ar pressure of $\sim 10^{5} \mathrm{~Pa}$ was applied to improve the fluidity of the melt to fill the mold. Moreover, in the $\mathrm{Mg}_{54} \mathrm{Cu}_{28} \mathrm{Ag}_{7} \mathrm{Y}_{11}$ alloy, the melt point and boiling point of $\mathrm{Mg}$ are both low; thus the $\mathrm{Mg}$ atoms in the overheating melt are energetic and active. It is then become harder that the atoms should be frozen into an amorphous solid. Thus, the GFA of the $\mathrm{Mg}_{54} \mathrm{Cu}_{28} \mathrm{Ag}_{7} \mathrm{Y}_{11}$ alloy may be decreased by the high casting temperature. In addition, the quartz tube can react with $\mathrm{Mg}$ melt, resulting in the reduction of $\mathrm{Mg}$ content. Therefore, the actual composition of the BMG plate may be changed deviating from the nominal composition which has the best GFA in this quaternary alloy system. The second aspect is related to the copper mold. In our opinion, the copper mold not only provides the high cooling rate during casting, but 
also supplies many favorable sites for heterogeneous nucleation. These both aspects mentioned above might jointly work during the injection casting process, resulting in the apparently abnormal surface crystallization.

\section{Conclusions}

In the present work, the $\mathrm{Mg}_{54} \mathrm{Cu}_{28} \mathrm{Ag}_{7} \mathrm{Y}_{11}$ bulk metallic glass plate was obtained by an injection casting method using copper mold. It has been found that several crystalline phases were formed close to the as-cast surface but did not exist in the internal part of the plate. The surface crystallization is attributed to the overheating of the melt and nucleation induced by the surface of copper mold. It is demonstrated that the function of copper mold to trigger heterogeneous nucleation cannot be totally ignored, although it provides the high cooling rate for glass formation during the casting.

\section{Conflict of Interests}

The author declares that there is no conflict of interests regarding the publication of this paper.

\section{References}

[1] A. L. Greer, "Metallic glasses," Science, vol. 267, no. 5206, pp. 1947-1953, 1995.

[2] H. W. Kui, A. L. Greer, and D. Turnbull, "Formation of bulk metallic glass by fluxing," Applied Physics Letters, vol. 45, no. 6, pp. 615-616, 1984.

[3] W. Klement, R. H. Willens, and P. Duwez, "Non-crystalline structure in solidified gold-silicon alloys," Nature, vol. 187, no. 4740, pp. 869-870, 1960.

[4] A. Inoue, T. Zhang, and T. Masumoto, "Production of amorphous cylinder and sheet of $\mathrm{La}_{55} \mathrm{Al}_{25} \mathrm{Ni}_{20}$ alloy by a metallic mold casting method," Materials Transactions JIM, vol. 31, no. 5, pp. 425-428, 1990.

[5] K. F. Yao, F. Ruan, Y. Q. Yang, and N. Chen, "Superductile bulk metallic glass," Applied Physics Letters, vol. 88, no. 12, Article ID 122106, 2006.

[6] K. F. Yao and C. Q. Zhang, "Fe-based bulk metallic glass with high plasticity," Applied Physics Letters, vol. 90, no. 6, Article ID 061901, 2007.

[7] X. Wang, Y. Shao, and K. F. Yao, "Chemical composition dependence of atomic oxygen erosion resistance in $\mathrm{Cu}$-rich bulk metallic glasses," Chinese Science Bulletin, vol. 57, no. 36, pp. 4801-4804, 2012.

[8] C. A. Schuh, T. C. Hufnagel, and U. Ramamurty, "Mechanical behavior of amorphous alloys," Acta Materialia, vol. 55, no. 12, pp. 4067-4109, 2007.

[9] A. L. Greer, K. L. Rutherford, and I. M. Hutchings, "Wear resistance of amorphous alloys and related materials," International Materials Reviews, vol. 47, no. 2, pp. 87-112, 2002.

[10] N. Chen, R. Frank, N. Asao et al., "Formation and properties of Au-based nanograined metallic glasses," Acta Materialia, vol. 59, no. 16, pp. 6433-6440, 2011.

[11] S. J. Pang, T. Zhang, K. Asami, and A. Inoue, "Synthesis of Fe-Cr-Mo-C-B-P bulk metallic glasses with high corrosion resistance," Acta Materialia, vol. 50, no. 3, pp. 489-497, 2002.
[12] P. Gong, K. F. Yao, and Y. Shao, "Lightweight Ti-Zr-Be-Al bulk metallic glasses with improved glass-forming ability and compressive plasticity," Journal of Non-Crystalline Solids, vol. 358, pp. 2620-2625, 2012.

[13] P. Gong, K. F. Yao, and Y. Shao, "Effects of Fe addition on glassforming ability and mechanical properties of Ti-Zr-Be bulk metallic glass," Journal of Alloys and Compounds, vol. 536, pp. 26-29, 2012.

[14] X. Wang, Y. Shao, P. Gong, and K. F. Yao, "Effect of thermal cycling on the mechanical properties of $\mathrm{Zr}_{41} \mathrm{Ti}_{14} \mathrm{Cu}_{12.5} \mathrm{Ni}_{10} \mathrm{Be}_{22.5}$ alloy," Science China-Physics Mechanics \& Astronomy, vol. 55, no. 12, pp. 2357-2361, 2012.

[15] A. Inoue, A. Kato, T. Zhang, S. G. Kim, and T. Masumoto, "Mg-Cu-Y amorphous alloys with high mechanical strengths produced by a metallic mold casting method," Materials Transactions JIM, vol. 32, no. 7, pp. 609-616, 1991.

[16] E. S. Park, H. G. Kang, W. T. Kim, and D. H. Kim, "Effect of Ag addition on the glass-forming ability of $\mathrm{Mg}-\mathrm{Cu}-\mathrm{Y}$ metallic glass alloys," Journal of Non-Crystalline Solids, vol. 279, no. 2-3, pp. 154-160, 2001.

[17] H. Ma, Q. Zheng, J. Xu, Y. Li, and E. Ma, "Doubling the critical size for bulk metallic glass formation in the $\mathrm{Mg}-\mathrm{Cu}-\mathrm{Y}$ ternary system," Journal of Materials Research, vol. 20, no. 9, pp. 22522255, 2005.

[18] H. Ma, L. L. Shi, J. Xu, Y. Li, and E. Ma, "Discovering inchdiameter metallic glasses in three-dimensional composition space," Applied Physics Letters, vol. 87, no. 18, Article ID 181915, pp. 1-3, 2005.

[19] Q. Zheng, J. Xu, and E. Ma, "High glass-forming ability correlated with fragility of $\mathrm{Mg}-\mathrm{Cu}(\mathrm{Ag})-\mathrm{Gd}$ alloys," Journal of Applied Physics, vol. 102, no. 11, Article ID 113519, 2007.

[20] J. S. C. Jang, S. R. Jian, T. H. Li, J. C. Huang, C. Y. A. Tsao, and C. T. Liu, "Structural and mechanical characterizations of ductile Fe particles-reinforced Mg-based bulk metallic glass composites," Journal of Alloys and Compounds, vol. 485, no. 12, pp. 290-294, 2009.

[21] J. S. C. Jang, Y. S. Chang, T. H. Li, P. J. Hsieh, J. C. Huang, and C. Y. A. Tsao, "Plasticity enhancement of $\mathrm{Mg}_{58} \mathrm{Cu}_{28.5} \mathrm{Gd}_{11} \mathrm{Ag}_{2.5}$ based bulk metallic glass composites dispersion strengthened by Ti particles," Journal of Alloys and Compounds, vol. 504, no. 1, pp. S102-S105, 2010.

[22] K. F. Xie, K. F. Yao, T. Y. Huang, and W. G. Liu, "A convenient and controllable induction melt-injection casting device under high vacuum," CN ZL200920110116.5, 2009.

[23] M. Mezbahul-Islam and M. Medraj, "Phase equilibrium in MgCu-Y,” Scientific Reports, vol. 3, p. 3033, 2013.

[24] A. Gebert, U. Wolff, A. John, and J. Eckert, "Corrosion behaviour of $\mathrm{Mg}_{65} \mathrm{Y}_{10} \mathrm{Cu}_{25}$ metallic glass," Scripta Materialia, vol. 43, no. 3, pp. 279-283, 2000.

[25] P. Gong, X. Wang, Y. Shao, N. Chen, X. Liu, and K. F. Yao, "A Ti-Zr-Be-Fe-Cu bulk metallic glass with superior glass-forming ability and high specific strength," Intermetallics, vol. 43, pp. 177-181, 2013.

[26] K. F. Xie, K. F. Yao, and T. Y. Huang, "Influence of the melting temperature on the fabrication of a Ti-Cu-Zr-Ni-Sn bulk metallic glass," Materials Science Forum, vol. 688, pp. 413418, 2011. 

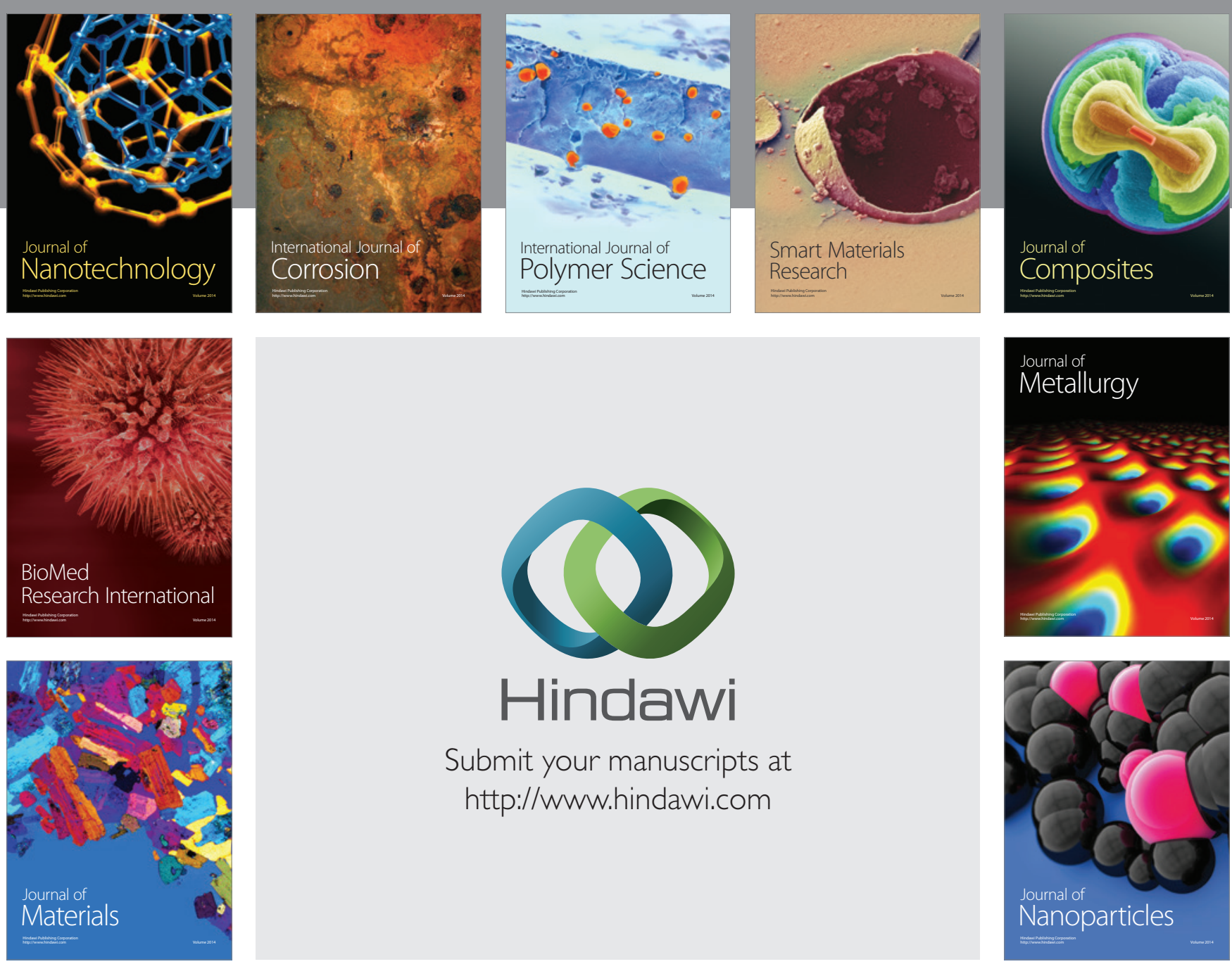

Submit your manuscripts at http://www.hindawi.com
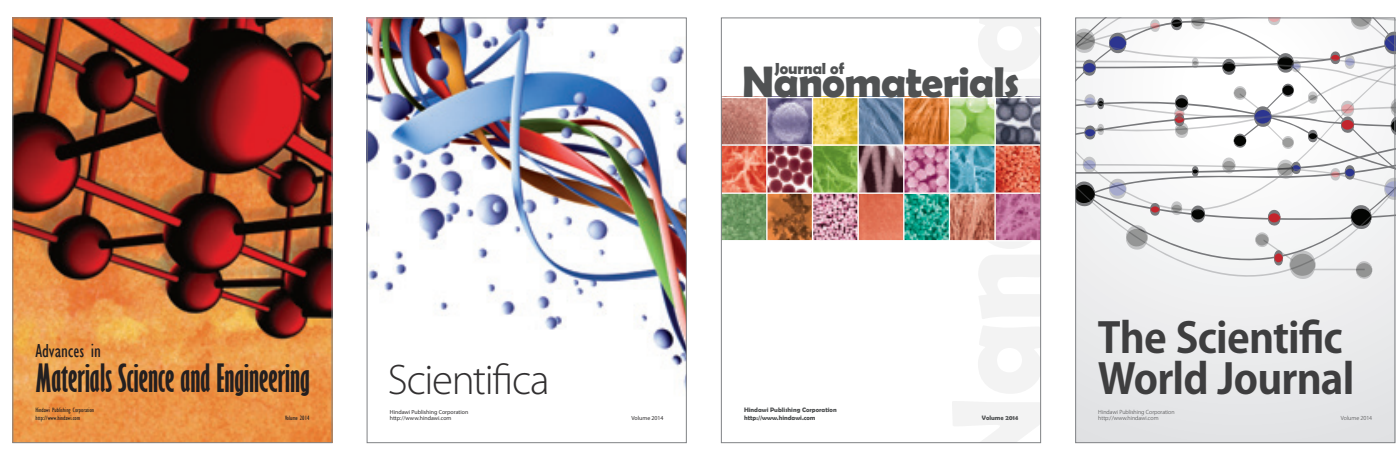

\section{The Scientific World Journal}
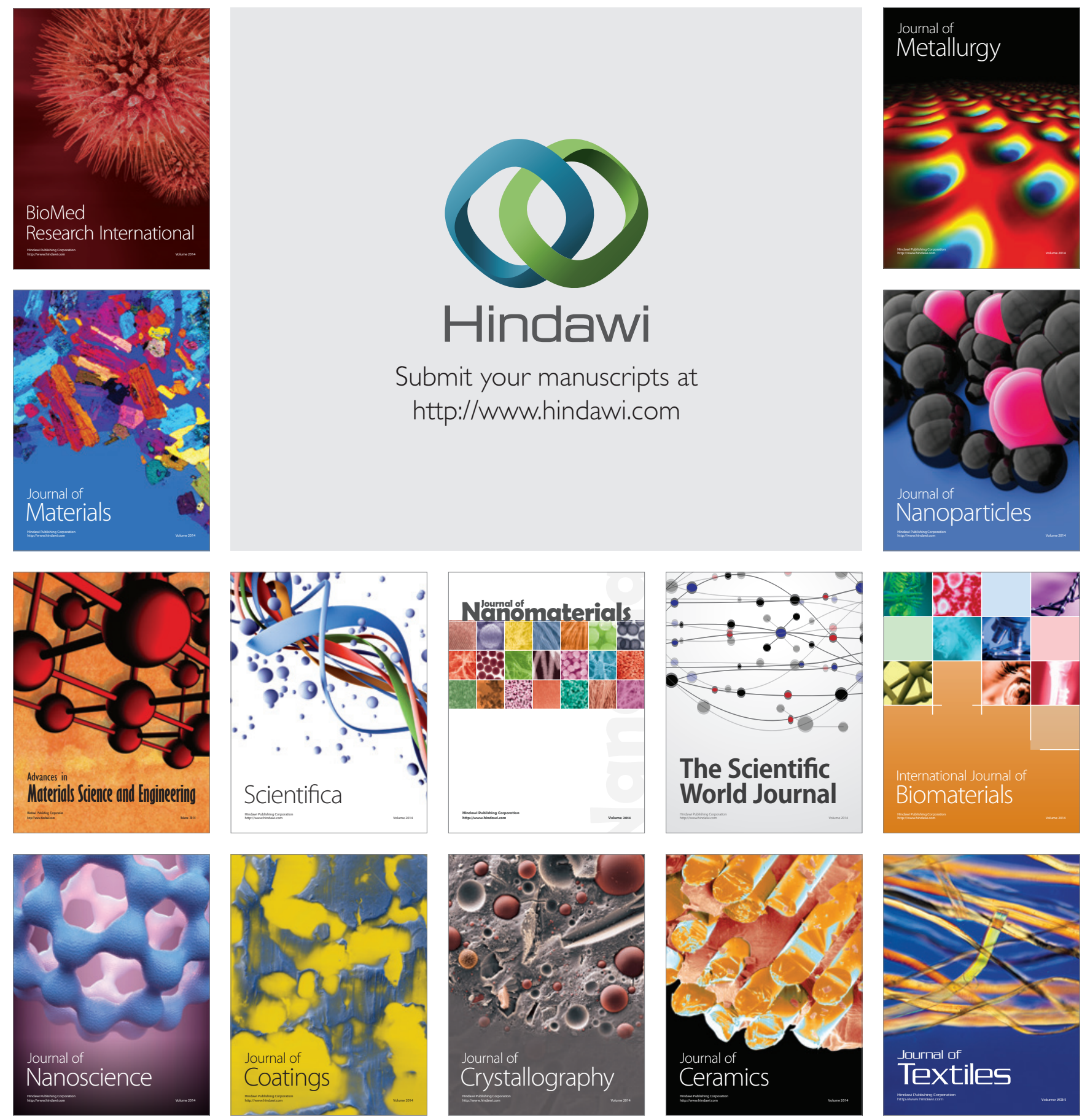